Pacific Journal of Mathematics

CONTINUOUS DEPENDENCE ON PARAMETERS AND
BOUNDARY DATA FOR NONLINEAR TWO-POINT BOUNDARY

Steven KenYon INGRA 


\section{CONTINUOUS DEPENDENCE ON PARAMETERS AND BOUNDARY DATA FOR NONLINEAR TWO-POINT BOUNDARY VALUE PROBLEMS}

\section{STEVEN K. IngraM}

Sufficient conditions are given for the continuous dependence of solutions to the two-point boundary value problem

$$
\begin{aligned}
x^{\prime \prime} & =f\left(t, x, x^{\prime} ; \mu\right) \\
x(a) & =\alpha \quad x(b)=\beta
\end{aligned}
$$

on the boundary data and the parameter $\mu$.

Previous results given by Gaines and Klaasen for continuous dependence on the boundary data have assumed continuity on $f$ and uniqueness to two-point BVP'S. Klaasen has also shown assuming uniqueness to two-point BVP'S and the existence of a $C^{2}$-solution to (1)-(2) that there exist solutions $x\left(t ; \alpha^{\prime}, \beta^{\prime}\right)$ to $(1)$ with the boundary conditions

$$
x(a)=\alpha^{\prime} \quad x(b)=\beta^{\prime}
$$

for all $\left(\alpha^{\prime}, \beta^{\prime}\right)$ sufficiently close to $(\alpha, \beta)$. Furthermore, $x\left(t ; \alpha^{\prime}, \beta^{\prime}\right)$ is a uniformly continuous function of $\left(\alpha^{\prime}, \beta^{\prime}\right)$ at $(\alpha, \beta)$ on $[a, b]$. This same result is shown to be valid under weaker uniqueness conditions. Sufficient conditions are also given for existence and continuous dependence on the parameter, $\mu$, of solutions to $(1)-(2)$.

We consider the BVP

$$
\begin{gathered}
x^{\prime \prime}=f\left(t, x, x^{\prime} ; \mu\right) \\
x(a)=\alpha \quad x(b)=\beta
\end{gathered}
$$

and assume

I. $f\left(t, x_{1}, x_{2} ; \mu\right)$ is continuous on $[a, b] \times R^{3}$

II. There exists a solution $x_{0}(t)$ to the BVP

$$
\begin{gathered}
x^{\prime \prime}=f\left(t, x, x^{\prime} ; \mu_{0}\right) \\
x(a)=\alpha_{0} \quad x(b)=\beta_{0}
\end{gathered}
$$

such that if $x(t)$ is any other solution to (3) and $x\left(t_{i}\right)=x_{0}\left(t_{i}\right), i=1$, 2 , for $a \leqq t_{1}<t_{2} \leqq b$, then $x(t) \equiv x_{0}(t)$ on $\left[t_{1}, t_{2}\right]$.

Following Jackson, [3], we make the following definition.

Definition 2.1. For any constant $C>0$, let 


$$
F^{*}\left(t, x, x^{\prime} ; \mu\right)=\left\{\begin{array}{l}
f(t, x, C ; \mu) \quad \text { if } \quad x^{\prime} \geqq C \\
f\left(t, x, x^{\prime} ; \mu\right) \text { if }\left|x^{\prime}\right| \leqq C \\
f(t, x,-C ; \mu) \text { if } \quad x^{\prime} \leqq-C
\end{array}\right.
$$

and define for $u(t) \leqq v(t)$ on $[a, b]$

$$
F\left(t, x, x^{\prime} ; \mu\right)=\left\{\begin{array}{l}
F^{*}\left(t, v(t), x^{\prime} ; \mu\right)+[x-v(t)]^{1 / 2} \text { if } x \geqq v(t) \\
F^{*}\left(t, x, x^{\prime} ; \mu\right) \text { if } u(t) \leqq x \leqq v(t) \\
F^{*}\left(t, u(t), x^{\prime} ; \mu\right)-[u(t)-x]^{1 / 2} \text { if } x \leqq u(t) .
\end{array}\right.
$$

Then $F\left(t, x, x^{\prime} ; \mu\right)$ is called the modification of $f\left(t, x, x^{\prime} ; \mu\right)$ with respect to $u(t), v(t)$ and $C$.

LEMMA 2.2. Under Conditions $I$ and $I I$, given $\varepsilon>0$ there exists constants $\sigma>0, C_{0}>0, C_{0}^{\prime}>0$ such that for any $t_{0} \in[a, b]$ and any $\alpha$, $\beta, \mu$ with $\left|x_{0}\left(t_{0}\right)-\alpha\right| \leqq \varepsilon,\left|x_{0}^{\prime}\left(t_{0}\right)-\beta\right| \leqq \varepsilon$ and $\left|\mu-\mu_{0}\right|<\varepsilon$ every solution $x(t ; \mu)$ to IVP

$$
\begin{gathered}
x^{\prime \prime}=f\left(t, x, x^{\prime} ; \mu\right) \\
x\left(t_{0}\right)=\alpha \quad x^{\prime}\left(t_{0}\right)=\beta
\end{gathered}
$$

or IVP

$$
\begin{gathered}
x^{\prime \prime}=F^{*}\left(t, x, x^{\prime} ; \mu\right) \\
x\left(t_{0}\right)=\alpha \quad x^{\prime}\left(t_{0}\right)=\beta
\end{gathered}
$$

exists on $\left[t_{0}-\delta, t_{0}+\delta\right]$ and satisfies $|x(t ; \mu)| \leqq C_{0}^{\prime},\left|x^{\prime}(t ; \mu)\right| \leqq C_{0}$ on $\left[t_{0}-\delta, t_{0}+\delta\right]$.

Proof. The proof is an easy application of the Peano existence theorem ([2], Theorem 2.1,) where

$$
C_{0}=\max _{[a, b]}\left|x_{0}^{\prime}(t)\right|+\varepsilon+1, C_{0}^{\prime}=\max _{[a, b]}\left|x_{0}(t)\right|+\varepsilon+1 .
$$

THeorem 2.3. Assume Conditions I and II. Then there exists a $\delta>0$ such that for all $\mu$ with $\left|\mu-\mu_{0}\right|<\delta$, a solution $x(t ; \mu)$ to BVP (1) - (4) exists. Furthermore, $x(t ; \mu) \rightarrow x_{0}(t)$ in $C^{1}$-norm on $[a, b]$ as $\mu \rightarrow \mu_{0}$.

Proof. Let $\left\{\mu_{n}\right\}$ be any sequence converging to $\mu$. It suffices to show that there is a subsequence $\left\{\mu_{n}^{*}\right\}$ such that for all $\mu_{n}^{*}$, a solution $x\left(t ; \mu_{n}^{*}\right)$ to $B V P(1)-(4)$ exists.

Denote by $\bar{x}_{m}\left(t ; \mu_{n}\right)$ a solution to (1) satisfying

$$
x(a)=\alpha_{0} \quad x^{\prime}(a)=x_{0}^{\prime}(a)+1 / m .
$$


Pick $\varepsilon=1$ and let $\delta, C_{0}, C_{0}^{\prime}$ be the constants assured by Lemma 2.2. For $n$ sufficiently large, say $n \geqq N,\left|\mu_{n}-\mu_{0}\right| \leqq 1$, and hence the sequences $\left\{\bar{x}_{m}\left(t ; \mu_{n}\right)\right\}_{n=N}^{\infty}$ and $\left\{\bar{x}_{m}^{\prime}\left(t ; \mu_{n}\right)\right\}_{n=N}^{\infty}$ are uniformly bounded and equicontinuous on $[a, a+\delta]$. By Ascoli's theorem there exists a subsequence $\left\{\bar{x}_{m}^{*}\left(t ; \mu_{n}\right)\right\}$, which converges in $C^{1}$-norm on $[a, a+\delta]$ to a solution $\bar{x}_{m}\left(t ; \mu_{0}\right)$ of IVP $(3)-(8)$. Letting $m \rightarrow \infty$, there exists a subsequence, $\left\{\bar{x}_{m}^{*}\left(t ; \mu_{0}\right)\right\}$, which converges in $C^{1}$-norm to a solution $z_{0}(t)$ of (3) satisfying the initial conditions

$$
x(a)=\alpha_{0} \quad x^{\prime}(a)=x_{0}^{\prime}(a) .
$$

Case 1. $z_{0}(t) \equiv x_{0}(t)$ on $[a, a+\delta]$. Given any $\varepsilon>0, \varepsilon<1$, there exists an $M$ and $N$ such that for all $m \geqq M$ and all $n \geqq N$,

$$
\left\|\bar{x}_{m}\left(t ; \mu_{n}\right)-x_{0}(t)\right\|_{c^{1}}<\varepsilon \text { on }[a, a+\delta]
$$

and

$$
\bar{x}_{m}\left(a+\delta ; \mu_{n}\right)>x_{0}(a+\delta) .
$$

By a similar procedure there exists a sequence $\left\{\underline{x}_{m}\left(t ; \mu_{n}\right)\right\}$ of solutions to equation (1) satisfying

$$
x(a)=\alpha_{0} \quad x^{\prime}(a)=x_{0}^{\prime}(a)-1 / m,
$$

such that for all $m$ and $n$ sufficiently large, (say $m \geqq M, n \geqq N$ without loss of generality),

$$
\left\|\underline{x}_{m}\left(t ; \mu_{n}\right)-x_{0}(t)\right\|_{C^{1}}<\varepsilon \text { on }[a, a+\delta]
$$

and

$$
\underline{x}_{m}\left(\alpha+\delta ; \mu_{n}\right)<x_{0}(\alpha+\delta) .
$$

By our uniqueness assumption in II, there exists an $N_{m}^{\prime} \geqq N$ such that for all $n \geqq N_{m}^{\prime}, \bar{x}_{m}\left(t ; \mu_{n}\right) \geqq \underline{x}_{m}\left(t ; \mu_{n}\right)$.

Now let $F_{m}\left(t, x, x^{\prime} ; \mu_{n}\right)$ be the modification of $f\left(t, x, x^{\prime} ; \mu_{n}\right)$ with respect to $\bar{x}_{m}\left(t ; \mu_{n}\right), \underline{x}_{m}\left(t ; \mu_{m}\right)$ and $C_{0}$ for any $n \geqq N_{m}^{\prime}$. By Theorem 2.5 , [3], there exists solutions $\bar{y}_{1}\left(t ; \mu_{n} ; j\right)$ and $\underline{y}_{1}\left(t ; \mu_{n} ; j\right)$ to BVP

$$
\begin{gathered}
x^{\prime \prime}=F_{m}\left(t, x, x^{\prime} ; \mu_{n}\right) \\
x(a)=\alpha_{0} \quad x(a+\delta)=x_{0}(a+\delta) \pm 1 / j,
\end{gathered}
$$

respectively, for all $j \geqq J$ where

$$
\underline{x}_{m}\left(a+\delta ; \mu_{n}\right) \leqq x_{0}(a+\delta)-1 / j<x_{0}(a+\delta)+1 / j \leqq \bar{x}_{m}\left(a+\delta ; \mu_{n}\right) .
$$

Furthermore,

$$
\underline{x}_{m}\left(t ; \mu_{n}\right) \leqq \bar{y}_{1}\left(t ; \mu_{n} ; j\right) \leqq \bar{x}_{m}\left(t ; \mu_{n}\right) \text { on }[a, a+\delta]
$$


and hence

$$
\left|\bar{y}_{1}^{\prime}\left(a ; \mu_{n}, j\right)-x_{0}^{\prime}(a)\right| \leqq 1 / m,
$$

implying by Lemma 2.2

$$
\left|\bar{y}_{1}^{\prime}\left(t ; \mu_{n} ; j\right)\right| \leqq C_{0} \quad \text { on }[a, a+\delta] \text {. }
$$

Thus $\bar{y}_{1}\left(t ; \mu_{n} ; j\right)$ is in fact a solution to

$$
x^{\prime \prime}=f\left(t, x, x^{\prime} ; \mu_{n}\right) \text {. }
$$

Similarly $\underline{y}_{1}\left(t ; \mu_{n} ; j\right)$ is a solution to $(19)$.

Now fix $j$. The sequences $\left\{\bar{y}_{1}\left(t ; \mu_{n} ; j\right)_{n=N_{m^{\prime}}}^{\infty}\right.$ and $\left\{\bar{y}_{1}^{\prime}\left(t ; \mu_{n} ; j\right)\right\}_{n=N_{m^{\prime}}}^{\infty}$ are uniformly bounded and equicontinuous, and hence a subsequence converges to a solution $\bar{y}_{1}\left(t ; \mu_{0} ; j\right)$ of (3) satisfying the boundary conditions

$$
x(a)=\alpha_{0} \quad x(a+\delta)=x_{0}(a+\delta)+1 / j .
$$

Similarly a subsequence of $\left\{\bar{y}_{1}\left(t ; \mu_{0} ; j\right)_{j=J}^{\infty}\right\}$ converges in $C^{1}$-norm on $[a, a+\delta]$ to $x_{0}(t)$ by II. By Lemma 2.2, then, there exists a $J^{\prime} \geqq J$ such that $\bar{y}_{1}\left(t ; \mu_{0} ; j\right)$ may be extended to $[a, a+2 \delta]$ for all $j \geqq J^{\prime}$. Then also for $n$ sufficiently large the solutions $\bar{y}_{1}\left(t ; \mu_{n} ; j\right)$ may be extended to $[a, a+2 \delta]$.

Similarly for $n$ and $j$ sufficiently large the solutions $\underline{y}_{1}\left(t ; \mu_{n} ; j\right)$ may be extended to $[a, a+2 \delta]$. We now use the solutions $\bar{y}_{1}\left(t ; \mu_{n} ; j\right)$ and $\underline{y}_{1}\left(t ; \mu_{n} ; j\right)$ in place of $\bar{x}_{m}\left(t ; \mu_{n}\right)$ and $\underline{x}_{m}\left(t ; \mu_{n}\right)$ and argue as above on the interval $[a, a+2 \delta]$.

We continue in this way until we may assume that there are sequences of solutions $\bar{y}\left(t ; \mu_{n} ; j\right)$ and $\underline{y}\left(t ; \mu_{n} ; j\right)$ to equation (11) satisfying

$$
x(a)=\alpha_{0} \quad x(b)=\beta_{0} \pm 1 / j,
$$

respectively ,

with $\bar{y}\left(t ; \mu_{n} ; j\right) \geqq \underline{y}\left(t ; \mu_{n} ; j\right)$ on $[a, b]$. Using the modification of $f\left(t, x, x^{\prime} ; \mu_{n}\right)$ with respect to $\bar{y}\left(t ; \mu_{n} ; j\right), \underline{y}\left(t ; \mu_{n} ; j\right)$, and $C_{0}$, and arguing as above we may assume that for some subsequence $\left\{\mu_{n}^{*}\right\}$ of $\left\{\mu_{n}\right\}$ there exists solutions $x\left(t ; \mu_{n}^{*}\right)$ to BVP $(11)-(4)$.

Case 2. $z_{0}(t) \neq x_{0}(t)$ on $[a, a+\delta]$. Then by II,

$$
z_{0}(a+\delta)>x_{0}(a+\delta) \text {. }
$$

Let

$$
0<\varepsilon<\min \left(1, z_{0}(a+\delta)-x_{0}(a+\delta)\right) .
$$

Similarly, if $\underline{x}_{m}\left(t ; \mu_{0}\right)$ does not converge to $x_{0}(t)$ on $[a, a+\delta]$, then for $n$ and $m$ sufficiently large 


$$
\underline{x}_{m}\left(a+\delta ; \mu_{n}\right)<x_{0}(a+\delta)-\varepsilon / 3 .
$$

Now we may obtain the solutions $\bar{y}_{1}\left(t ; \mu_{n} ; j\right)$ and $\underline{y}_{1}\left(t ; \mu_{n} ; j\right)$ and proceed as in Case 1.

Case 3. In Case 1 we considered the possibility that the sequences $\left\{\bar{x}_{m}\left(t ; \mu_{0}\right)\right\}$ and $\left\{\underline{x}_{m}\left(t ; \mu_{0}\right)\right\}$ had subsequences which converged to $x_{0}(t)$ on $[a, a+\delta]$. In Case 2, these sequences converged to functions not identically equal to $x_{0}(t)$ on $[a, a+\delta]$. In Case 3 , then, we must consider the possibility that one of these sequences converges to $x_{0}(t)$ and the other converges to some function not identically equal to $x_{0}(t)$ on $[a, a+\delta]$. The proof for Case 3 is thus just a combination of the proofs of Case 1 and Case 2.

To complete the proof of the theorem we must show that $x\left(t ; \mu_{n}^{*}\right) \rightarrow$ $x_{0}(t)$ in $C^{1}$-norm on $[a, b]$ as $n \rightarrow \infty$. By construction we have

$$
\left|x\left(t ; \mu_{n}^{*}\right)\right| \leqq \max _{[a, b]}\left|x_{0}(t)\right|+1
$$

and

$$
\left|x^{\prime}\left(t ; \mu_{n}^{*}\right)\right| \leqq C_{0} \quad \text { on }[a, b] \text {. }
$$

Thus the sequences $\left\{x\left(t ; \mu_{n}^{*}\right)\right\}$ and $\left\{x^{\prime}\left(t ; \mu_{n}^{*}\right)\right\}$ are uniformly bounded and equicontinuous on $[a, b]$ and hence by Ascoli's Theorem there exists a further subsequence which converges in $C^{1}$-norm on $[a, b]$ to a solution of BVP (3) - (4) which by II must be $x_{0}(t)$. Similarly any subsequence of $\left\{x\left(t ; \mu_{n}^{*}\right)\right\}$ has a further subsequence which converges to $x_{0}(t)$ implying that the original sequence itself must converge to $x_{0}(t)$.

Note. We have proven only a weak form of continuous dependence on the parameter; i.e., we have shown only that the solutions $x\left(t ; \mu_{n}\right)$ must converge to $x_{0}(t)$. It is still unknown whether all solutions to BVP (11) - (4) must converge to $x_{0}(t)$ as $\mu \rightarrow \mu_{0}$.

Theorem 2.3 is of interest when considering nonlinear eigenvalue problems. If an eigenvalue problem satisfies Conditions I and II, then the set of eigenvalues is dense in itself.

We now seek sufficient conditions for existence and continuous dependence of solutions to BVP's in which we vary not only the parameter but also the boundary data.

Lemma 3.4. Assume $I$ and II. Then there exists sequences of solutions $\left\{u_{n}(t)\right\},\left\{v_{n}(t)\right\},\left\{w_{n}(t)\right\}$ and $\left\{z_{n}(t)\right\}$ that converge to $x_{0}(t)$ in the $C^{1}$-norm on $[a, b]$ and such that

$$
u_{n}(a)=x_{0}(a) \quad u_{n}(b)>u_{n+1}(b)>x_{0}(b) \quad \text { for all } n,
$$




$$
\begin{array}{rll}
v_{n}(b)=x_{0}(b) & v_{n}(a)>v_{n+1}(a)>x_{0}(a) & \text { for all } n, \\
w_{n}(a)=x_{0}(a) & w_{n}(b)<w_{n+1}(b)<x_{0}(b) & \text { for all } n,
\end{array}
$$

and

$$
z_{n}(b)=x_{0}(b) \quad z_{n}(a)<z_{n+1}(a)<x_{0}(a) \quad \text { for all } n,
$$

Proof. The proof is contained in the proof of Theorem 3.7, [5].

Theorem 2.5. Under Conditions $I$ and II, there exist sequences $\left\{\bar{x}_{n}(t)\right\}$ and $\left\{\underline{x}_{n}(t)\right\}$ of solutions to (3) which converge to $x_{0}(t)$ in $C^{1}$-norm on $[a, b]$ from above and below, respectively, with

$$
\bar{x}_{n}(a)>\bar{x}_{n+1}(a)>x_{0}(a)>\underline{x}_{n+1}(a)>\underline{x}_{n}(a)
$$

and

$$
\bar{x}_{n}(b)>\bar{x}_{n+1}(b)>x_{0}(b)>\underline{x}_{n+1}(b)>\underline{x}_{n}(b)
$$

for all $n$.

Proof. We will show the existence of $\left\{\bar{x}_{n}(t)\right\}$. Let $S_{1}$ be the set of all $t_{0} \in[a, b]$ such that there exists a second solution $x_{1}(t)$ to IVP

$$
\begin{gathered}
x^{\prime \prime}=f\left(t, x, x^{\prime} ; \mu_{0}\right) \\
x\left(t_{0}\right)=x_{0}\left(t_{0}\right) \quad x^{\prime}\left(t_{0}\right)=x_{0}^{\prime}\left(t_{0}\right)
\end{gathered}
$$

with $x_{1}(t)>x_{0}(t)$ on $\left(\lambda_{1}^{-}, t_{0}\right) \cap[a, b]$ for some $\lambda_{1}^{-}<t_{0}$. Let $t_{1}=\inf S_{1}$. If $S_{1}=\phi$, let $t_{1}=b$. Similarly, let $S_{2}$ be the set of all $t_{0} \in[a, b]$ such that there exists a second solution $x_{2}(t)$ to IVP (3) - (14) with $x_{2}(t)>x_{0}(t)$ on $\left(t_{0}, \lambda_{2}^{+}\right) \cap[a, b]$ for some $\lambda_{2}^{+}>t_{0}$, and let $t_{2}=\sup S_{2}$. If $S_{2}=\phi$, let $t_{2}=a$.

Case 1. $t_{1}<t_{2}$. Then there are solutions $x_{i}(t), i=1,2$ to IVP (3) - (14) for $t_{0} \in\left[t_{1}, t_{2}\right]$ satisfying

$$
x_{1}(t)>x_{0}(t) \quad \text { for some } t<t_{0}
$$

and

$$
x_{2}(t)>x_{0}(t) \quad \text { for some } t>t_{0} .
$$

By Lemma 2.2 all solutions to IVP (3) - (14) exist on $\left[t_{0}-\delta, t_{0}+\delta\right]$ for some $\delta>0$. Assume $t_{0}+\delta>t_{2}$ and hence $x_{2}\left(t_{0}+\delta\right)>x_{0}\left(t_{0}+\delta\right)$. By Knesser's Theorem, ([2], Theorem 4.1, page 15), there exist solutions $\left\{u_{n}(t)\right\}$ to IVP (3) - (14) on $\left[t_{0}, t_{0}+\delta\right]$ such that $u_{n}\left(t_{0}+\delta\right) \rightarrow$ $x_{0}\left(t_{0}+\delta\right)$ as $n \rightarrow \infty$. By Kamke's convergence theorem, ([2], Theorem 3.2, page 14), and our uniqueness assumption, there exists a subsequence $\left\{u_{n}^{*}(t)\right\}$ which converges to $x_{0}(t)$ in $C^{1}$-norm on $\left[t_{0}, b\right]$ with 


$$
u_{n}(b)>u_{n+1}(b)>x_{0}(b) \quad \text { for all } n .
$$

If $x_{2}(t) \equiv x_{0}(t)$ on $\left[t_{0}, t_{0}+\delta\right]$ we continue to the right until there is an interval $\left[t_{3}, t_{3}+\delta\right]$ such that $x_{2}(t) \equiv x_{0}(t)$ on $\left[t_{0}, t_{3}\right]$ and

$$
x_{2}\left(t_{3}+\delta\right)>x_{0}\left(t_{3}+\delta\right) \text {. }
$$

Then argue as above.

Similarly there are solutions $v_{n}(t)$ to IVP (3) - (14) which converge to $x_{0}(t)$ in $C^{1}$-norm on $\left[a, t_{0}\right]$ with

$$
v_{n}(a)>v_{n+1}(a)>x(a), \quad \text { for all } n \text {. }
$$

Then define

$$
\bar{x}_{n}(t)= \begin{cases}v_{n}(t) & \text { on }\left[a, t_{0}\right] \\ u_{n}(t) & \text { on }\left[t_{0}, b\right] .\end{cases}
$$

$\left\{\bar{x}_{n}(t)\right\}$ is the required sequence.

Case 2. $t_{1} \geqq t_{2}$. We claim in this case that there exist solutions $\left\{u_{n}(t)\right\}$ and $\left\{v_{n}(t)\right\}$ as given in Lemma 2.4 with

$$
u_{n}\left(t_{0}\right)=v_{n}\left(t_{0}\right) \quad \text { for some } t_{0} \in\left[t_{1}, t_{2}\right], \quad \text { for all } n
$$

sufficiently large. To see this, given $\varepsilon^{\prime}>0$, let $\delta^{\prime}, C_{0}$, and $C_{0}^{\prime}$ be the constants assured by Lemma 2.2. Choose $\varepsilon>0$ so small that

$$
\varepsilon<\varepsilon^{\prime}
$$

and

$$
\delta \equiv \frac{2 \varepsilon}{\varepsilon^{\prime}}<\varepsilon^{\prime} .
$$

Thus there exists an $N$ such that

$$
\left\|u_{N}(t)-x_{0}(t)\right\|_{C^{1}}<\varepsilon \quad \text { on }\left[a, t_{0}\right]
$$

Since $t_{1} \geqq t_{2}$ we may assume $u_{N}\left(t_{0}\right)>x_{0}\left(t_{0}\right)$ and hence

$$
x_{0}\left(t_{0}\right)<v_{n}\left(t_{0}\right)<u_{N}\left(t_{0}\right) \text { for all } n \text { sufficiently large, }
$$

say $n \geqq N^{\prime}$. By [3], Theorem 2.5, there exists a solution $x_{n}(t)$ to BVP

$$
\begin{aligned}
& x^{\prime \prime}=F\left(t, x, x^{\prime} ; \mu_{0}\right) \\
& x(a)=\alpha \quad x\left(t_{0}\right)=v_{n}\left(t_{0}\right) \quad \text { for all } n \geqq N^{\prime},
\end{aligned}
$$

where $F\left(t, x, x^{\prime} ; \mu_{0}\right)$ is the modification of $f\left(t, x, x^{\prime} ; \mu_{0}\right)$ with respect to $x_{0}(t), u_{N}(t)$ and $C_{0}$. Furthermore 


$$
x_{0}(t) \leqq x_{n}(t) \leqq u_{N}(t) \quad \text { on }\left[a, t_{0}\right]
$$

Hence

$$
\left|x_{n}^{\prime}(t)-x_{0}^{\prime}(t)\right| \nsupseteq \varepsilon^{\prime}
$$

on any subinterval of $\left[\alpha, t_{0}\right]$ of length $\delta=2 \varepsilon / \varepsilon^{\prime}$. But this in turn implies that

$$
\left|x_{n}^{\prime}(t)\right| \leqq C_{0}
$$

on any subinterval of length $\delta$ and hence

$$
\left|x_{n}^{\prime}(t)\right| \leqq C_{0} \quad \text { on }\left[a, t_{0}\right] \text {. }
$$

By definition of $F\left(t, x, x^{\prime} ; \mu_{0}\right), x_{n}(t)$ is a solution to (3). Now for $n$ sufficiently large we may extend the solution $x_{n}(t)$ to $[a, b]$ and use them as the solutions $u_{n}(t)$ assured by Lemma 2.4.

Let $\varepsilon>0$ be arbitrary, but fixed, and let $\delta, C_{0}$, and $C_{0}^{\prime}$ be the constants assured by Lemma 2.2. There exists an $N>0$ such that for all $n \geqq N$

$$
\left\|u_{n}(t)-x_{0}(t)\right\|_{C^{1}}<\varepsilon
$$

and

$$
\left\|v_{n}(t)-x_{0}(t)\right\|_{c^{1}}<\varepsilon .
$$

Suppose for definiteness that $u_{N}^{\prime}\left(t_{0}\right) \geqq v_{N}^{\prime}\left(t_{0}\right)$. Define

$$
C_{1}^{N}=\left\{\left(x, x^{\prime}\right): v_{N}\left(t_{0}\right)=u_{N}\left(t_{0}\right)=x, \quad v_{N}^{\prime}\left(t_{0}\right) \leqq x^{\prime} \leqq u_{N}^{\prime}\left(t_{0}\right)\right\} .
$$

$C_{1}^{N}$ is a compact connected set in $R^{2}$. Let $C_{2}^{N}$ be the set of all $\left(\beta, \beta^{\prime}\right)$ such that there exists a solution $x\left(t ; \alpha, \alpha^{\prime}\right)$ to (3) with $x\left(t_{0}\right)=\alpha$, $x^{\prime}\left(t_{0}\right)=\alpha^{\prime}$, where

$$
\left(\alpha, \alpha^{\prime}\right) \in C_{1}^{N}, x\left(t_{0}-\delta ; \alpha, \alpha^{\prime}\right)=\beta
$$

and

$$
x^{\prime}\left(t_{0}-\delta ; \alpha, \alpha^{\prime}\right)=\beta^{\prime} .
$$

By an extension of Knesser's Theorem, ([6], page 386), $C_{2}^{N}$ is a compact connected set in $R^{2}$ containing the two points $\left(u_{N}\left(t_{0}-\delta\right), u_{N}^{\prime}\left(t_{0}-\delta\right)\right)$ and $\left(v_{N}\left(t_{0}-\delta\right), v_{N}^{\prime}\left(t_{0}-\delta\right)\right)$.

$$
C_{2}^{N} \subset \overline{N_{\varepsilon}\left(x_{0}\left(t_{0}-\delta\right), x_{0}^{\prime}\left(t_{0}-\delta\right)\right)} .
$$

In this case $\left|\beta-x_{0}\left(t_{0}-\delta\right)\right| \leqq \varepsilon$ and $\left|\beta^{\prime}-x_{0}^{\prime}\left(t_{0}-\delta\right)\right| \leqq \varepsilon$ for all $\left(\beta, \beta^{\prime}\right) \in C_{2}^{N}$. Hence the solutions $x\left(t ; \alpha, \alpha^{\prime}\right)$ may be continued to $\left[t_{0}-2 \delta, t_{0}\right]$. Similarly, we may continue these solutions to the left by $\delta$ intervals as long as the end points of each solution lie inside 
the $\varepsilon$-tube about $x_{0}(t)$. Let $n_{0}$ be such that

$$
t_{0}-\left(n_{0}-1\right) \delta \geqq a>t_{0}-n_{0} \delta
$$

and suppose that

$$
C_{n}^{N} \subset \overline{N_{\varepsilon}\left(x_{0}\left(t_{0}-(n-1) \delta\right), x_{0}^{\prime}\left(t_{0}-(n-1) \delta\right)\right)}
$$

for all $n \leqq n_{0}$. Thus all solutions $x\left(t ; \alpha, \alpha^{\prime}\right)$ may be continued to $\left[a, t_{0}\right]$.

We now perform a similar procedure to the right of $t_{0}$. Define $D_{1}^{N}=C_{1}^{N}$ and $D_{n}^{N}$ analogously to $C_{n}^{N}$. Assume also in (i) that

$$
D_{n}^{N} \subset \overline{N_{\varepsilon}\left(x_{0}\left(t_{0}+(n-1) \delta\right), x_{0}^{\prime}\left(t_{0}+(n-1) \delta\right)\right)} \text { for all } n \leqq n_{0}^{\prime},
$$

where

$$
t_{0}+\left(n_{0}^{\prime}-1\right) \delta<b \leqq t_{0}+n_{0}^{\prime} \hat{0} .
$$

Define $C_{a}^{N}$ to be the set of all $\left(\gamma, \gamma^{\prime}\right)$ such that there exists a solution $x(t)$ to IVP

$$
\begin{gathered}
x^{\prime \prime}=f\left(t, x, x^{\prime} ; \mu_{0}\right) \\
x\left(t_{0}-\left(n_{-1}\right) \delta\right)=\beta, x^{\prime}\left(t_{0}-\left(n_{-1}\right) \delta\right)=\beta^{\prime}
\end{gathered}
$$

with $\left(\beta, \beta^{\prime}\right) \in C_{n_{0}-1}^{N}$ and $x(a)=\gamma, x^{\prime}(a)=\gamma^{\prime}$. Analogously, define $D_{b}^{N}$.

Now for each $\left(\gamma, \gamma^{\prime}\right) \in C_{a}^{N}$ with $\gamma>x_{0}(\alpha)$, there exists a solution $x\left(t ; \gamma, \gamma^{\prime}\right)$ on $[a, b]$ such that $x\left(a ; \gamma, \gamma^{\prime}\right)=\gamma, x^{\prime}\left(a ; \gamma, \gamma^{\prime}\right)=\gamma^{\prime}, x\left(t_{0} ; \gamma, \gamma^{\prime}\right)=$ $u_{N}\left(t_{0}\right)=v_{N}\left(t_{0}\right)$ and $\left(x\left(b ; \gamma, \gamma^{\prime}\right), x^{\prime}\left(b ; \gamma, \gamma^{\prime}\right)\right) \in D_{b}^{N}$. If $x\left(b ; \gamma, \gamma^{\prime}\right)>x_{0}(b)$, we've found an $\bar{x}(t)$. Hence suppose $x\left(b ; \gamma, \gamma^{\prime}\right) \leqq x_{0}(b)$ for all $\left(\gamma, \gamma^{\prime}\right) \in C_{a}^{N}$ with $\gamma>x_{0}(a)$. Pick $\left\{\gamma_{n}\right\} \rightarrow x_{0}(a), \gamma_{n}>x_{0}(a)$ for all $n$. By Lemma 2.2, we have

$$
\left|x\left(t ; \gamma_{n}, \gamma_{n}^{\prime}\right)\right|<C_{0}^{\prime}
$$

and

$$
\left|x^{\prime}\left(t ; \gamma_{n}, \gamma_{n}^{\prime}\right)\right|<C_{0} \quad \text { for all } t \in[a, b] \text {. }
$$

By Ascoli's Theorem there exists a subsequence $\left\{x^{*}\left(t ; \gamma_{n}, \gamma_{n}^{\prime}\right)\right\}$ which converges in $C^{1}$-norm to a solution $z(t)$ on $[a, b]$. But $z(a)=$ $x_{0}(a), z(b) \leqq x_{0}(b)$, and $z\left(t_{0}\right)=u_{N}\left(t_{0}\right)>x_{0}\left(t_{0}\right)$ contradicting our uniqueness assumption. We may thus assume that we have an $\bar{x}_{1}(t)$. Also by II and the definition of $t_{0}, \bar{x}_{1}(t)>x_{0}(t)$ on $[a, b]$. Now let

$$
\varepsilon^{\prime}=\min _{[a, b]}\left(\bar{x}_{1}(t)-x_{0}(t)\right)>0 .
$$

Using this $\varepsilon^{\prime}$ in place of $\varepsilon$ we may procede to find an $\bar{x}_{2}(t)$ as long as (i) occurs. 
(ii) Suppose for some $n$,

$$
C_{n}^{N} \not \subset \overline{N_{\varepsilon}\left(x_{0}\left(t_{0}-(n-1) \delta\right), x_{0}^{\prime}\left(t_{0}(n-1) \delta\right)\right)} .
$$

Then all solutions $x\left(t ; \alpha, \alpha^{\prime}\right)$ for $\left(\alpha, \alpha^{\prime}\right) \in C_{1}^{N}$ may not be extendable to $\left[a, t_{0}\right]$. However, if we let ${ }^{u} C_{n}^{N}$ and ${ }^{v} C_{n}^{N}$ be the components of

$$
C_{n}^{N} \cap \overline{N_{\varepsilon}\left(x_{0}\left(t_{0}-(n-1) \delta\right), x_{0}^{\prime}\left(t_{0}-(n-1) \delta\right)\right)}
$$

which contain $\left(u_{N}\left(t_{0}-(n-1) \delta\right), u_{N}^{\prime}\left(t_{0}-(n-1) \delta\right)\right)$ and $\left(v_{N}\left(t_{0}-(n-1) \delta\right)\right.$, $\left.v_{N}^{\prime}\left(t_{0}-(n-1) \delta\right)\right)$ respectively, then we may continue the solutions ending in ${ }^{u} C_{n}^{N}$ or ${ }^{v} C_{n}^{N}$ as before.

Let $C_{1}^{N^{\prime}}=\left\{\left(\alpha, \alpha^{\prime}\right):\left(\alpha, \alpha^{\prime}\right) \in C_{1}^{N}\right.$ and $x\left(t ; \alpha, \alpha^{\prime}\right)$ exists on $\left[a, t_{0}\right]$ by the extension procedure above $\}$. It is easy to see that $C_{1}^{N^{\prime}}$ is a compact interval. Analogously we define the compact set $D_{1}^{N^{\prime}}$.

(a) $\quad C_{1}^{N^{\prime}}=C_{1}^{N}=D_{1}^{N}=D_{1}^{N^{\prime}}$. Thus $x\left(t ; \alpha, \alpha^{\prime}\right)$ exists on $[a, b]$ for all $\left(\alpha, \alpha^{\prime}\right) \in C_{1}=D_{1}$. Suppose no $x\left(t ; \alpha, \alpha^{\prime}\right)$ satisfies $x\left(\alpha ; \alpha, \alpha^{\prime}\right)>x_{0}(\alpha)$ and $x\left(b ; \alpha, \alpha^{\prime}\right)>x_{0}(b)$.

Let $\alpha_{0}^{\prime}=\sup \left\{\alpha^{\prime}: u_{N}^{\prime}\left(t_{0}\right) \geqq \alpha^{\prime} \geqq v_{N}^{\prime}\left(t_{0}\right), x\left(a ; \alpha, \alpha^{\prime}\right)>x_{0}(a)\right.$, and $\left(\alpha, \alpha^{\prime}\right) \in$ $\left.C_{1}^{N}\right\}$. By an application of Ascoli's Theorem, there exists a solution $z_{1}(t)$ with $z_{1}(b) \leqq x_{0}(b), z_{1}(a)>x_{0}(a), z_{1}\left(t_{0}\right)>x_{0}\left(t_{0}\right)$, and $z_{1}^{\prime}\left(t_{0}\right)=\alpha_{0}^{\prime}$. By uniqueness $\alpha_{0}^{\prime}<u^{\prime}\left(t_{0}\right)$ and hence there exists a sequence $\left\{\alpha_{m}^{\prime}\right\} \rightarrow \alpha_{0}^{\prime}$ with $\alpha_{0}^{\prime}<\alpha_{m}^{\prime} \leqq u_{n}^{\prime}\left(t_{0}\right)$ and a sequence of solutions $x\left(t ; \alpha, \alpha_{m}^{\prime}\right)$ such that $x\left(a ; \alpha, \alpha_{m}^{\prime}\right) \leqq x_{0}(a)$. By Ascoli's Theorem again there exists a subsequence converging in $C^{1}$-norm to a solution $z_{2}(t)$ with $z_{2}^{\prime}\left(t_{0}\right)=\alpha_{0}^{\prime}$ and $z_{2}(a) \leqq x_{0}(a)$. The solution

$$
z(t)= \begin{cases}z_{2}(t) & \text { on }\left[a, t_{0}\right] \\ z_{1}(t) & \text { on }\left[t_{0}, b\right]\end{cases}
$$

contradicts our uniqueness assumption. We must conclude that there exists an $x\left(t ; \alpha, \alpha^{\prime}\right)$ such that $x\left(a ; \alpha, \alpha^{\prime}\right)>x_{0}(a)$ and $x\left(b ; \alpha, \alpha^{\prime}\right)>x_{0}(b)$. We then define $\bar{x}(t) \equiv x\left(t ; \alpha, \alpha^{\prime}\right)$ and continue as before.

(b) $C_{1}^{N^{\prime}} \neq C_{1}^{N}, D_{1}^{N}=D_{1}^{N^{\prime}}$. Let $\alpha_{0}^{\prime}=\sup \left\{\alpha^{\prime}: v_{N}^{\prime}\left(t_{0}\right) \leqq \alpha^{\prime} \leqq u_{N}^{\prime}\left(t_{0}\right)\right.$ and such that there exists a solution $x^{r}\left(t ; \alpha, \alpha^{\prime}\right)$ to IVP

$$
\begin{gathered}
x^{\prime \prime}=f\left(t, x, x^{\prime} ; \mu_{0}\right) \\
x\left(t_{0}\right)=u_{N}\left(t_{0}\right) \quad x^{\prime}\left(t_{0}\right)=\alpha^{\prime}
\end{gathered}
$$

which exists on $\left[t_{0}, b\right]$ and satisfies $\left.x^{r}\left(b ; \alpha, \alpha^{\prime}\right) \leqq x_{0}(b)\right\}$. Then $\alpha_{0}^{\prime}<u_{N}^{\prime}\left(t_{0}\right)$ by uniqueness. Let $\alpha_{m}^{\prime} \rightarrow \alpha_{0}^{\prime}, \alpha_{0}^{\prime}<\alpha_{m}^{\prime} \leqq u_{N}^{\prime}\left(t_{0}\right)$ for all $m$. Let $x^{1}\left(t ; \alpha, \alpha_{m}^{\prime}\right)$ be a solution to IVP (3) - (15) on some interval $\left[\lambda^{-}, t_{0}\right]$. By Kamke's convergence theorem a subsequence of $\left\{x^{1}\left(t ; \alpha, \alpha_{m}^{\prime}\right)\right\}$ converges to a solution $x_{N}\left(t ; \alpha, \alpha_{0}^{\prime}\right)$ at least on $\left[t-\delta, t_{0}\right]$. If $x_{N}\left(t ; \alpha, \alpha_{0}^{\prime}\right)$ exists on 
$[a, b]$, then $x^{1}\left(t ; \alpha, \alpha_{m}^{\prime}\right)$ exists on $[a, b]$ for $m$ sufficiently large and $x^{1}\left(a ; \alpha, \alpha_{m}^{\prime}\right)>x_{0}(a)$ since $x_{N}\left(\alpha ; \alpha, \alpha_{0}^{\prime}\right)>x_{0}(a)$. But $x\left(b ; \alpha, \alpha_{m}^{\prime}\right)>x_{0}(b)$ by definition of $\alpha_{0}^{\prime}$ and we have our $\bar{x}_{1}(t)$.

At this point let us do a similar analysis with $u_{N+K}(t)$ and $v_{N+K}(t)$ for $K=1,2, \cdots$. We wish to show that $x_{N+K}\left(t ; \alpha_{K}, \alpha_{K_{0}}^{\prime}\right)$ fails to exist on $\left[a, t_{0}\right]$ for at most a finite number of indices $K$. Suppose for contradiction $x_{N+K}\left(t ; \alpha_{K}, \alpha_{K_{0}}^{\prime}\right)$ does not exist on $\left[a, t_{0}\right]$ for $K=1,2, \cdots$, relabeling if necessary. Since $\left(\alpha_{K}, \alpha_{K_{0}}^{\prime}\right) \rightarrow\left(x_{0}\left(t_{0}\right), x_{0}^{\prime}\left(t_{0}\right)\right)$, by Kamke's convergence theorem a subsequence of $\left\{x_{N+K}\left(t ; \alpha_{K}, \alpha_{K_{0}}^{\prime}\right)\right\}_{K=1}^{\infty}$ converges to a solution $z(t)$ of the IVP (3) - (14) in $C^{1}$-norm on some interval $\left(\omega^{-}, t_{0}\right]$. By definition of $t_{1}, z(t) \leqq x_{0}(t)$ on $\left(\omega^{-}, t_{0}\right]$ and by uniqueness of $x_{0}(t), z(t) \geqq x_{0}(t)$. Hence $z(t) \equiv x_{0}(t)$ and thus for $K$ sufficiently large $x_{N+K}\left(t ; \alpha_{K}, \alpha_{K_{0}}^{\prime}\right)$ exists on $\left[\alpha, t_{0}\right]$, which is a contradiction. Thus for all but perhaps a finite number of cases in which (b) occurs we obtain an $\bar{x}_{1}(t)$.

(c) $C_{1}^{N^{\prime}} \neq C_{1}^{N}$ and $D_{1}^{N^{\prime}} \neq D_{1}^{N}$ with

$$
\left[C_{1}^{N}-\left({ }^{u} C_{1}^{N} \cup{ }^{v} C_{1}^{N}\right)\right] \cap\left[D_{1}^{N}-\left({ }^{u} D_{1}^{N} \cup{ }^{v} D_{1}^{N}\right)\right] \neq \dot{\phi} .
$$

Again we claim (c) can happen for at most a finite number of indices $K$ without obtaining a suitable $\bar{x}_{1}(t)$. Suppose for contradiction that (c) occurs for $K=1,2, \cdots$. Pick $\alpha_{K}^{\prime}$ such that

$$
v_{N+K}^{\prime}\left(t_{0}\right)<\alpha_{K}^{\prime}<u_{N+K}^{\prime}\left(t_{0}\right)
$$

with $\alpha_{K}^{\prime} \in\left[C_{1}^{N+K}-\left({ }^{u} C_{1}^{N+K} \cup{ }^{u} C_{1}^{N+K}\right)\right] \cap\left[D_{1}^{N+K}-\left({ }^{u} D_{1}^{N+K} \cup{ }^{v} D_{1}^{N+K}\right)\right]$. Then if we assume $x\left(t ; \alpha_{K}, \alpha_{K}^{\prime}\right)$ does not exist on $[a, b]$ and argue as in (b) we arrive at a contradiction.

(d) $C_{1}^{N^{\prime}} \neq C_{1}^{N}, D_{1}^{N^{\prime}} \neq D_{1}^{N}$ with

$$
\left[C_{1}^{N}-\left({ }^{u} C_{1}^{N} \cup{ }^{v} C_{1}^{N}\right)\right] \cap\left[D_{1}^{N}-\left({ }^{u} D_{1}^{N} \cup{ }^{v} D_{1}^{N}\right)\right]=\phi .
$$

In this case $C_{1}^{N}-\left({ }^{u} C_{1}^{N} \cup{ }^{v} C_{1}^{N}\right)$ is a subset of ${ }^{u} D_{1}^{N} \cup{ }^{v} D_{1}^{N}$ and we may proceed as in (b) to show that this can occur without obtaining a suitable $\bar{x}(t)$ for at most a finite number of indices $K$.

Hence (b), (c), and (d) are inconclusive for at most a finite number of indices. We may thus conclude that an $\bar{x}_{1}(t)$ exists, and as before $\bar{x}_{1}(t)>x_{0}(t)$ on $[a, b]$. Letting $\varepsilon^{\prime}=\min _{[a, b]}\left(\bar{x}_{1}(t)-x_{0}(t)\right)>0$ and using $\varepsilon^{\prime}$ in place of $\varepsilon$, we may repeat the above procedure to obtain an $\bar{x}_{2}(t)$ with $x_{0}(t)<\bar{x}_{2}(t)<\bar{x}_{1}(t)$ on $[a, b]$ and so on.

Similarly we may construct $\{\underline{x}(t)\}$.

Theorem 2.5 generalizes a result of Klaasen, [4], Corollary 7, where he assumes uniqueness to two-point BVP'S (3) - (2). The following example shows that Condition II does not imply uniqueness to two-point BVP'S in any neighborhood of $x_{0}(t)$. 
ExAMPLE 2.6 Define

$$
f\left(t, x, x^{\prime} ; \mu\right)=\left\{\begin{array}{l}
2 \cdot 3^{3 / 4} \cdot \mu \cdot\left|x^{\prime}\right|^{1 / 4}|x|^{1 / 6} \quad \text { if } x \geqq 0 \\
0 \quad \text { if } x \leqq 0 .
\end{array}\right.
$$

Then $f\left(t, x, x^{\prime} ; \mu\right)$ is continuous on $[-1,1] \times R^{2}$, and

$$
x_{c}(t)=\left\{\begin{array}{ll}
(t-c)^{3} & \text { if } t \geqq c \\
(c-t)^{3} & \text { if } t \leqq c
\end{array} c \in[-1,1]\right.
$$

is a solution to the differential equation

$$
x^{\prime \prime}(t)=f\left(t, x, x^{\prime} ; 1\right)
$$

on $[-1,1]$ for any $c \in[-1,1]$. Also $x_{0}(t) \equiv 0$ is a solution satisfying Condition II. However, $x_{\varepsilon}(t) \equiv \varepsilon$ is a solution for any $\varepsilon>0$ and $x_{c}(t)$ intersects $x_{\varepsilon}(t)$ twice if $c \in\left[-1+\varepsilon^{1 / 3}, 1-\varepsilon^{1 / 2}\right]$.

Definition 2.7. Let $x(t ; \mu)$ be a solution to (1). We will say that solutions to (1) are unique with respect to $x(t ; \mu)$ on $[a, b]$ if $x(t)$ is any other solution to (1) with $x\left(t_{i}\right)=x\left(t_{i} ; \mu\right), i=1,2$ for any $t_{1}, t_{2}$ satisfying $a \leqq t_{1}<t_{2} \leqq b$, then

$$
x(t) \equiv x(t ; \mu) \text { on }\left[t_{1}, t_{2}\right] \text {. }
$$

THEOREM 2.8. Assume, in addition to $I$ and II, that solutions to $B V P$ 's (3) - (2) are unique if they exist. By Theorem 2.3, there exist a $\delta>0$ such that for all $\left|\mu-\mu_{0}\right|<\delta$, a solution $x(t ; \mu)$ to $B V P$ (1) - (4) exists. Assume also that solutions to (1) are unique with respect to $x(t ; \mu)$ for all $\left|\mu-\mu_{0}\right|<\delta$. Let $\varepsilon>0$ be given sufficiently small. Then there exists $a \delta^{\prime} \leqq \delta$ such that for all $\left|\mu-\mu_{0}\right|<\delta^{\prime}$, there exists a solution $x(t ; \mu ; \alpha, \beta)$ to $B V P(1)-(2)$ where

$$
\left|\alpha-\alpha_{0}\right|<\varepsilon,\left|\beta-\beta_{0}\right|<\varepsilon \text {. }
$$

Furthermore, $x(t ; \mu ; \alpha, \beta) \rightarrow x_{0}(t)$ in $C^{1}$-norm on $[a, b]$ as $\mu \rightarrow \mu_{0}$, $\alpha \rightarrow \alpha_{0}$, and $\beta \rightarrow \beta_{0}$.

Proof. If suffices to show that if $\left\{\mu_{n}\right\}$ is any sequence converging to $\mu_{0}$, then there is a subsequence, relabeled the same, such that for all $n$, there exists a solution $x\left(t ; \mu_{n} ; \alpha, \beta\right)$ to BVP (11) - (2) for any $\left|\alpha-\alpha_{0}\right|<\varepsilon$ and $\left|\beta-\beta_{0}\right|<\varepsilon$, and that $x\left(t ; \mu_{n} ; \alpha, \beta\right) \rightarrow x_{0}(t)$ as $n \rightarrow \infty$, $\alpha \rightarrow \alpha_{0}$ and $\beta \rightarrow \beta_{0}$

Since solutions to BVP's (3) - (2) are unique if they exist, by Theorem 2.5 there exist sequences $\left\{\bar{x}_{m}\left(t ; \mu_{0}\right)\right\}_{m=1}^{\infty}$ and $\left\{\underline{x}_{m}\left(t ; \mu_{0}\right)\right\}_{m=1}^{\infty}$ which converge to $x_{0}(t)$ in the $C^{1}$-norm on $[a, b]$ with 


$$
\bar{x}_{m}\left(a ; \mu_{0}\right)>x_{0}(a)>\underline{x}_{m}\left(a ; \mu_{0}\right)
$$

and

$$
\bar{x}_{m}\left(b ; \mu_{0}\right)>x_{0}(b)>\underline{x}_{m}\left(b ; \mu_{0}\right) .
$$

Let $\delta^{\prime \prime}$ and $C_{0}$ be the constant assured by Lemma (2.2) for $\varepsilon=1$, and let $\varepsilon^{\prime}=\min \left(1 / 2, \delta^{\prime \prime} / 4\right)$. Then there exists an $M$ such that for $m \geqq M$

$$
\left\|\bar{x}_{m}\left(t ; \mu_{0}\right)-x_{0}(t)\right\|_{c^{1}}<\varepsilon^{\prime}
$$

and

$$
\left\|\underline{x}_{m}\left(t ; \mu_{0}\right)-x_{0}(t)\right\|_{0^{1}}<\varepsilon^{\prime}
$$

Fix $m \geqq M$ and let

$$
\begin{array}{r}
0<\varepsilon<\min \left(\varepsilon^{\prime}, 1 / 2\left(\bar{x}_{m}(a)-x_{0}(a)\right), 1 / 2\left(\bar{x}_{m}(b)-x_{0}(b)\right) .\right. \\
1 / 2\left(x_{0}(a)-\underline{x}_{m}(a)\right), 1 / 2\left(x_{0}(b)-\underline{x}_{m}(b)\right) .
\end{array}
$$

(This puts an upper bound on the possible choices of $\varepsilon$ ). By Theorem 2.3 there exists a subsequence of $\left\{\mu_{n}\right\}$, relabeled the same, and an $N>0$ such that for $n \geqq N$ there exist solutions $\bar{x}_{m}\left(t ; \mu_{n}\right)$ and $\underline{x}_{m}\left(t ; \mu_{n}\right)$ to equation (11) satisfying

$$
x(a)=\bar{x}_{m}\left(a ; \mu_{0}\right) \quad x(b)=\bar{x}_{m}\left(b ; \mu_{0}\right)
$$

and

$$
x(a)=\underline{x}_{m}\left(a ; \mu_{0}\right) \quad x(b)=\underline{x}\left(b ; \mu_{0}\right), \quad \text { respectively } .
$$

with

$$
\begin{aligned}
& \left\|\bar{x}_{m}\left(t ; \mu_{n}\right)-\bar{x}_{m}\left(t ; \mu_{0}\right)\right\|_{O^{1}}<\varepsilon \\
& \left\|\underline{x}_{m}\left(t ; \mu_{n}\right)-\underline{x}_{m}\left(t ; \mu_{0}\right)\right\|_{0^{1}}<\varepsilon .
\end{aligned}
$$

Let $F\left(t, x, x^{\prime} ; \mu_{n}\right)$ be the modification of $f\left(t, x, x^{\prime} ; \mu_{n}\right)$ with respect to $\bar{x}\left(t ; \mu_{n}\right), \underline{x}\left(t ; \mu_{n}\right)$ and $C_{0}$. By Theorem 2.5, [3], there exists a solution $x\left(t ; \mu_{n} ; \alpha, \beta\right)$ to $x^{\prime \prime}=F\left(t, x, x^{\prime} ; \mu_{n}\right)$ satisfying (2) for all $n \geqq N$, provided $\left|\alpha-x_{0}(\alpha)\right|<\varepsilon$ and $\left|\beta-x_{0}(b)\right|<\varepsilon$, with

$$
\underline{x}_{m}\left(t ; \mu_{n}\right) \leqq x\left(t ; \mu_{n} ; \alpha, \beta\right) \leqq \bar{x}_{m}\left(t ; \mu_{n}\right) \quad \text { on }[a, b] \text {. }
$$

Again it is easy to show that $x\left(t ; \mu_{n} ; \alpha, \beta\right)$ is a solution to (11).

It remains to show that $x\left(t ; \mu_{n} ; \alpha, \beta\right) \rightarrow x_{0}(t)$ as $n \rightarrow \infty, \alpha \rightarrow \alpha_{0}$ and $\beta \rightarrow \beta_{0}$. Let $\left\{\alpha_{m}\right\}$ be any sequence converging to $\alpha_{0}$ and $\left\{\beta_{m}\right\}$ any sequence converging to $\beta_{0}$. By construction the sequences $\left\{x\left(t ; \mu_{n} ; \alpha_{m}, \beta_{m}\right)\right\}$ and $\left\{x^{\prime}\left(t ; \mu_{n} ; \alpha_{m}, \beta_{m}\right)\right\}$ are uniformly bounded and equicontinuous on $[a, b]$. Hence there exists a subsequence which converges in $C^{1}$-norm on $[a, b]$ to $x_{0}(t)$ by the uniqueness of $x_{0}(t)$. This implies that $x(t ; \mu ; \alpha, \beta) \rightarrow x_{0}(t)$ as $\mu \rightarrow \mu_{0}, \alpha \rightarrow \alpha_{0}$, and $\beta \rightarrow \beta_{0}$. 


\section{REFERENCES}

1. R. Gaines, Continuous dependence for two-point boundary value problems, Pacific J. Math., 28 (1969), 327-336.

2. P. Hartman, Ordinary Differential Equations, John Wiley and Sons, New York (1964).

3. L. K. Jackson, Subfunctions and second order ordinary differential inequalities, Advances in Math., 2 (1968) 307-363.

4. G. Klaasen, Dependence of solutions on boundary conditions for second order ordinary differential equations, J. Diff. Eqs., 7 (1970), 24-33.

5. - Boundary Value Problems for Second Order Ordinary Differential Equations, a thesis presented to Univ. of Nebraska, (1968).

6. G. A. Sell, On the fundamental theory of ordinary differential equations, J. Diff. Eqs., 1 (1965) 370-392.

Received September 23, 1970. Portions of this paper are part of a doctoral thesis written under the supervision of Professor Jerrold W. Bebernes at the University of Colorado and supported in part by NSF Grant GP-11605.

NORWICH UNIVERSITY 


\section{PACIFIC JOURNAL OF MATHEMATICS}

\section{EDITORS}

\author{
H. SAMELSON \\ Stanford University \\ Stanford, California 94305

\section{R. HoвBY} \\ University of Washington \\ Seattle, Washington 98105
}

\section{J. DugundJI}

Department of Mathematics University of Southern California Los Angeles, California 90007

\author{
RichaRd ARENS \\ University of California \\ Los Angeles, California 90024
}

\section{ASSOCIATE EDITORS}
E. F. BECKENBACH
B. H. NEUMANN
F. WOLF
K. YoshidA

\section{SUPPORTING INSTITUTIONS}

\author{
UNIVERSITY OF BRITISH COLUMBIA \\ CALIFORNIA INSTITUTE OF TECHNOLOGY \\ UNIVERSITY OF CALIFORNIA \\ MONTANA STATE UNIVERSITY \\ UNIVERSITY OF NEVADA \\ NEW MEXICO STATE UNIVERSITY \\ OREGON STATE UNIVERSITY \\ UNIVERSITY OF OREGON \\ OSAKA UNIVERSITY
}

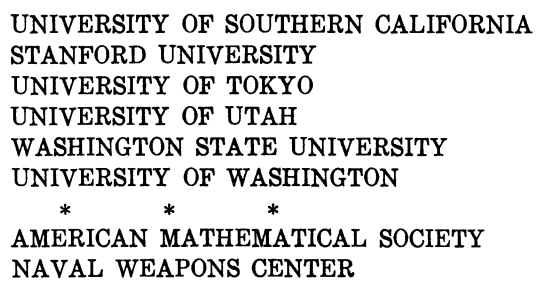

The Supporting Institutions listed above contribute to the cost of publication of this Journal, but they are not owners or publishers and have no responsibility for its content or policies.

Mathematical papers intended for publication in the Pacific Journal of Mathematics should be in typed form or offset-reproduced, (not dittoed), double spaced with large margins. Underline Greek letters in red, German in green, and script in blue. The first paragraph or two must be capable of being used separately as a synopsis of the entire paper. The editorial "we" must not be used in the synopsis, and items of the bibliography should not be cited there unless absolutely necessary, in which case they must be identified by author and Journal, rather than by item number. Manuscripts, in dup icate if possible, may be sent to any one of the four editors. Please classify according to the scheme of Math. Rev. Index to Vol. 39. All other communications to the editors should be addressed to the managing editor, Richard Arens, University of California, Los Angeles, California, 90024.

50 reprints are provided free for each article; additional copies may be obtained at cost in multiples of 50 .

The Pacific Journal of Mathematics is published monthly. Effective with Volume 16 the price per volume (3 numbers) is $\$ 8.00$; single issues, $\$ 3.00$. Special price for current issues to individual faculty members of supporting institutions and to individual members of the American Mathematical Society: $\$ 4.00$ per volume; single issues $\$ 1.50$. Back numbers are available.

Subscriptions, orders for back numbers, and changes of address should be sent to Pacific Journal of Mathematics, 103 Highland Boulevard, Berkeley, California, 94708.

PUBLISHED BY PACIFIC JOURNAL OF MATHEMATICS, A NON-PROFIT CORPORATION

Printed at Kokusai Bunken Insatsusha (International Academic Printing Co., Ltd.), 270, 3-chome Totsuka-cho, Shinjuku-ku, Tokyo 160, Japan. 


\section{Pacific Journal of Mathematics}

\section{Vol. 41, No. 2 December, 1972}

Tom M. (Mike) Apostol, Arithmetical properties of generalized Ramanujan sums .......................................... 281

David Lee Armacost and William Louis Armacost, On p-thetic groups ........ 295

Janet E. Mills, Regular semigroups which are extensions of groups .......... 303

Gregory Frank Bachelis, Homomorphisms of Banach algebras with minimal ideals ................................................ 307

John Allen Beachy, A generalization of injectivity .................. 313

David Geoffrey Cantor, On arithmetic properties of the Taylor series of rational functions. II.........................................

Václáv Chvátal and Frank Harary, Generalized Ramsey theory for graphs. III.

Small off-diagonal numbers .................................. 335

Frank Rimi DeMeyer, Irreducible characters and solvability of finite groups . . . . 347

Robert P. Dickinson, On right zero unions of commutative semigroups........ 355

John Dustin Donald, Non-openness and non-equidimensionality in algebraic

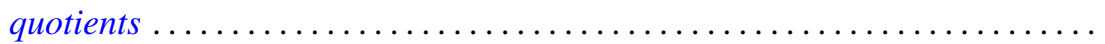

John D. Donaldson and Qazi Ibadur Rahman, Inequalities for polynomials with a prescribed zero ........................................ 375

Robert E. Hall, The translational hull of an $N$-semigroup ................ 379

John P. Holmes, Differentiable power-associative groupoids.............. 391

Steven Kenyon Ingram, Continuous dependence on parameters and boundary data for nonlinear two-point boundary value problems .

Robert Clarke James, Super-reflexive spaces with bases ..........

Gary Douglas Jones, The embedding of homeomorphisms of the plane in

continuous flows...............................

Mary Joel Jordan, Period $H$-semigroups and $t$-semisimple periodic

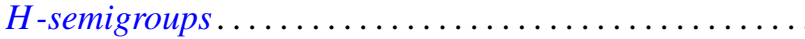

Ronald Allen Knight, Dynamical systems of characteristic 0

Kwangil Koh, On a representation of a strongly harmonic ring by sheaves...

Hui-Hsiung Kuo, Stochastic integrals in abstract Wiener space. ..

Thomas Graham McLaughlin, Supersimple sets and the problem of extending a

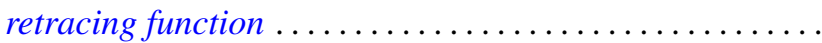

William Nathan, Open mappings on 2-manifolds .

M. J. O'Malley, Isomorphic power series rings

Sean B. O'Reilly, Completely adequate neighborhood systems and metrization

Qazi Ibadur Rahman, On the zeros of a polynomial and its derivative...

Russell Daniel Rupp, Jr., The Weierstrass excess function ..

Hugo Teufel, A note on second order differential inequalities and functional

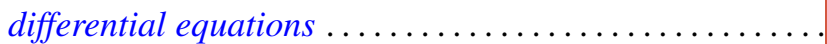

M. J. Wicks, A general solution of binary homogeneous equations over free 